\title{
Molecular detection of Torque teno virus in different breeds of swine
}

\author{
Zhiwei Wu, Hongning Wang ${ }^{*}$, Xin Yang, Zhongbing Guan and Yingshun Zhou
}

\begin{abstract}
Background: Torque teno virus (TTV), of the Anelloviridae family, lotatorquevirus genus, is a non-enveloped, singlestranded, and negative sense DNA (ssDNA) virus infecting human and many domestic animals including swines. Very little information is known about the investigations of TTV prevalence in different swine breeds so far.

Methods: In this study, 208 serum samples collected from seven swine breeds (Rongchang pig, Chenghua pig, Zibet pig, Wild boar, Duroc, Landrace, Large Yorkshire) from two independent farms were detected to determine the prevalence of two swine TTV genogroups, TTV1 and TTV 2, by nested polymerase chain reaction methods, and to analyse prevalence difference among these breeds.

Results: The results showed that the prevalence of TTV in the seven breeds was $92 \%-100 \%$. No significant difference ( $p>0.05)$ in TTV infection was observed between different breeds. Interestingly, significantly higher prevalence for TTV1 in Rongchang boars (90\%) and for TTV2 in Rongchang sows (95\%) were detected, while COinfection rate (43.8\%) was lower than other breeds. Sequence analysis showed that the homology of TTV1 and TTV2 were over $90.9 \%$ and $86.4 \%$ in these breeds, respectively.

Conclusions: The results indicated that TTV was widely distributed in the seven swine breeds. The prevalence of both TTV genogroups associated with swine breeds and genders. This study also respented the first description of swine TTV prevalence in different swine breeds. It was vitally necessary to further study swine TTV pathogenicity.
\end{abstract}

Keywords: nested polymerase chain reaction (nested PCR), serums, swine breeds, Torque teno virus (TTV)

\section{Background}

Torque teno virus (TTV) was first found from a Japanese patient with post-transfusional hepatitis of unknown etiology (non-A-G) in 1997 [1]. TTV is a small, non-enveloped, single-stranded, negative sense, and circular DNA virus, belonging to the Anelloviridae family, Iotatorquevirus genus $[2,3]$. TTV is frequently detected in humans and swines, but its pathogenicity/ virulence and its ability to induce specific diseases are currently unknown $[4,5]$. However, TTV co-infection with other virus species could be related with such a disease but to date no definitive correlation has been found with any disease syndrome [6-10]. The swine TTV genogroup 2 has been found to be more common

\footnotetext{
*Correspondence: whongning@163.com

School of Life science, Sichuan University, Animal Disease Prevention and Food Safety Key Laboratory of Sichuan Province,"985"Project Science Innovative Platform for Resource and environment Protection of Southwestern, Key Laboratory of Bio-resources and Eco-environment of Ministry of Education, Chengdu, Sichuan, 610065, P.R. China
}

in pig suffering from postweaning multisystemic wasting syndrome (PMWS), a disease caused by porcine circovirus type 2 (PCV2), than in non-infected pigs. Recent reports showed that porcine TTV partially contributed to inducing PMWS, porcine reproductive and respiratory syndrome (PRRS), porcine dermatits and nephriopathy syndrome and hepatitis of pigs infection [5,11-15]. Furthermore, the same family virus, Torque teno sus viruses (TTSuV), infection has been confirmed with cases of PCV2 infection, PRRSV infection but no research has been proved a contribution of the TTSuV in such conditions [11-13].

Torque teno virus (TTV) is able to infect several vertebrate species, including human, swine, chicken, sheep, cattle, dogs, and cats $[16,17]$. Analysis of genomic DNA reveals a well-conserved genomic organization among the various TTV species $[3,18]$. However, the TTVs that infect different vertebrate species show different genome lengths and a great variability in the sequences. The
C Biomed Central

(c) 2011 Wu et al; licensee BioMed Central Ltd. This is an Open Access article distributed under the terms of the Creative Commons Attribution License (http://creativecommons.org/licenses/by/2.0), which permits unrestricted use, distribution, and reproduction in any medium, provided the original work is properly cited. 
genome ranges from $2.1 \mathrm{~kb}$ to $3.8 \mathrm{~kb}$ in size. The genomes of TTVs infecting humans and chimpanzees range from 3.7 to $3.9 \mathrm{~kb}$ in size, those infecting pigs and dogs are 2.8 to $2.9 \mathrm{~kb}$ in length, respectively, and the TTV with the smallest genome identified to date, $2.1 \mathrm{~kb}$, has been detected in the cat [3]. TTV contains 3 or 4 partially overlapping open reading frames (ORF1, ORF2, ORF3 and/or ORF4) translated from negative ssDNA as well as a short stretch of untranslated region (UTR) with high GC content [17]. Nested PCR amplifications of the conserved regions in the UTR of TTV genogroup 1 and TTV genogroup 2, respectively, have been widely used [19].

The widespread prevalence of TTV in swine has been found in many countries, including USA, Canada, China, Thailand, Korea, Italy, Franc and Spain, varying between $24 \%$ and $100 \%$ by the nested PCR methods [20-23]. Detection of the European wild boars (sus scorfa) indicates a high prevalence of TTV [24]. In addition, TTV have been described in a large number of species $[17,25]$, and multiple infections of porcine TTV with distinct genotypes or subtypes was found in the same pig $[4,26]$.

The goal of this study was to detect, using speciesspecifc UTR nested PCR methods, the presence of TTV genogroup 1 and 2 in serum samples of swines of seven breeds from different farms, genders and age groups, and to further insight on its epidemiological characteristics.

\section{Results}

In this study, the results from TTV nested PCR detection in serum samples from seven breeds of pig were summarized in Table 1. In all detected serum samples, TTV1 or TTV2, TTV1, TTV2, and co-infected with both TTV genogroups were for $96.2 \%$ (200/208), $77.9 \%$ $(162 / 208), 82.2 \%(171 / 208)$, and $65.4 \%(136 / 208)$ for nested PCR positive, respectively. No significant difference on the prevalence between TTV1 and TTV2 was observed in all serum samples tested $(p>0.05)$. Prevalence difference between both TTV genogroups was mainly caused by the factors of swine breeds, and seondly for genders, age groups, and farms.

In the seven breeds of pig, the prevalence of TTV1 or TTV2 ranged from $92 \%$ to $100 \%$. The TTV1 and TTV2 co-infection was between $43.8 \%$ and $90.6 \%$. For TTV1, infection rates ranged from $68.8 \%$ to $90.6 \%$, and between $70 \%$ and $100 \%$ for TTV2 (Table 1). In the same breed, TTV2 prevalence was higher than TTV1 except Chenghua pig, and no significant difference on the TTV prevalence between these breeds was observed $(\rho>0.05)$.

In addition, prevalence of both TTV genogroups were analyzed according to the age classes, genders and farms of residence of pigs. The swine breed was the main contributors to the variation in prevalence observed among different age groups, genders and farms. Infection rates of TTV1 or TTV2 in post-weaning piglets, sub-adults, and adults were 93.3\% (98/105), 98.3\% (58/59), and 100\% (44/44), repectively. Results showed that significantly more post-weaning piglets tested were positive for TTV1, but infection rates of TTV2 was higher in the adults (Figure 1). In general, the difference in prevalence of both TTV genogroups was not significant between sexes in the seven breeds. For TTV1, prevalence in boar and sows populations ranged from $60 \%$ (3/5 in Yorkshire) to $100 \%$ (6/6 in Zibet pig), 61.7\% (37/60 in Rongchang pig) to $100 \%$ (14/14 in Duroc), respectively. For TTV2, prevalence in boar and sows populations were between $45 \%$ (9/20 in Rongchang pig) and 100\% (6/6 in Zibet pig, 18/ 18 in Duroc, 5/5 in Large Yorkshire), 78.6\% (11/14 in

Table 1 Prevalence of TTV genogroups in different breeds of pig

\begin{tabular}{|c|c|c|c|c|c|c|c|c|c|}
\hline \multirow[t]{3}{*}{ Farm } & \multirow[t]{3}{*}{ Breed } & \multicolumn{8}{|c|}{ Prevalence of swine TTV genogroup } \\
\hline & & \multicolumn{2}{|c|}{ TTV1 or TTV2 } & \multicolumn{2}{|c|}{ TTV1 } & \multicolumn{2}{|c|}{ TTV2 } & \multicolumn{2}{|c|}{ TTV1 and TTV2 } \\
\hline & & Positive & Prevalence & Positive & Prevalence & Positive & Prevalence & Positive & Prevalence \\
\hline \multirow[t]{4}{*}{ A } & Chenghua pig $(n=25)$ & 23 & $92.0 \%$ & 20 & $80.0 \%$ & 19 & $76.0 \%$ & 18 & $72.0 \% a, b$ \\
\hline & Rongchang pig $(\mathrm{n}=38)$ & 37 & $97.4 \%$ & 26 & $68.4 \%$ & 25 & $65.8 \%$ & 16 & $42.1 \%$ a \\
\hline & Wild boar $(n=20)$ & 19 & $95.0 \%$ & 15 & $75.0 \%$ & 16 & $80.0 \%$ & 12 & $60.0 \% \mathrm{a}, \mathrm{b}$ \\
\hline & Zibet pig $(n=10)$ & 10 & $100 \%$ & 9 & $90.0 \%$ & 10 & $100 \%$ & 9 & $90.0 \% \mathrm{~b}$ \\
\hline Total & $n=93$ & 89 & $95.7 \%$ & 70 & $75.3 \%$ & 70 & $75.3 \%$ & 55 & $59.1 \%$ \\
\hline \multirow[t]{4}{*}{$B$} & Landrace $(n=25)$ & 24 & $96.0 \%$ & 21 & $84.0 \%$ & 23 & $92.0 \%$ & 20 & $80.0 \% a, b$ \\
\hline & Large Yorkshire $(\mathrm{n}=16)$ & 16 & $100 \%$ & 13 & $81.5 \%$ & 15 & $93.4 \%$ & 13 & $81.5 \% \mathrm{a}, \mathrm{b}$ \\
\hline & Rongchang pig $(n=42)$ & 39 & $92.9 \%$ & 29 & $69.0 \%$ & 31 & $73.8 \%$ & 19 & $45.2 \%$ a \\
\hline & Duroc $(n=32)$ & 32 & $100 \%$ & 29 & $90.6 \%$ & 32 & $100 \%$ & 29 & $90.6 \%$ b \\
\hline Total & $n=115$ & 111 & $96.5 \%$ & 92 & $80.0 \%$ & 101 & $87.8 \%$ & 81 & $70.4 \%$ \\
\hline
\end{tabular}

Number of analyzed serum samples from different swine breeds in each farms ( $n$ ), total amount of positive animals, prevalence of in percentage, different farms $(A, B)$, and different letters $(a, b, c)$ within the same column mean statiscal significant differences in different breeds and sources TTV prevalence when comparing one breed/source to another. 


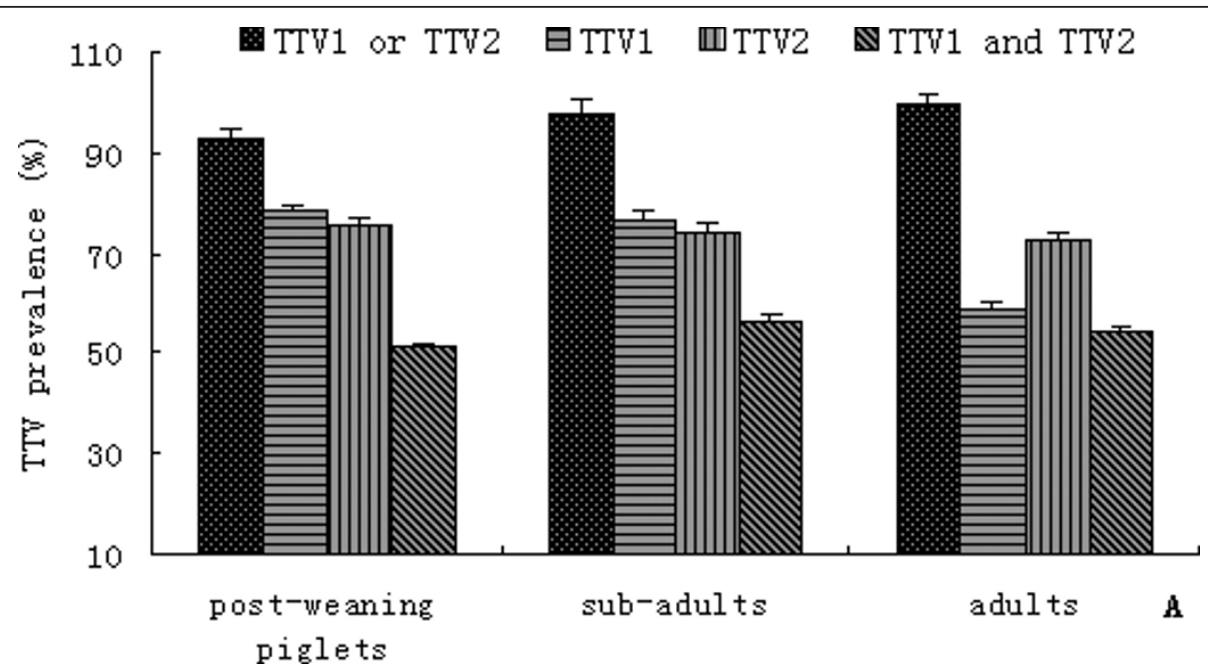

Figure 1 Mean prevalence of TTV genogroup 1 or TTV genogroup 2, TTV genogroup 1, TTV genogroup 2, and co-infection of both TTV geongroups in swines from different age classes.

Chenghua pig) and 100\% (4/4 in Zibet pig, 14/14 in Duroc, $12 / 12$ in Landrace, $11 / 11$ in Large Yorkshire), respectively (Table 2). An exception was found in the Rongchang swine, which the infection rates were significantly higher for TTV1 in Rongchang male pigs (90\%, 18/20) and for TTV2 in Rongchang female pigs (95\%, $47 /$ 60 ), while co-infection rates $(40 \%$ for male, $45 \%$ for female) was lower than the other breeds (Figure 2). In different farms, no significant difference of TTV infection was observed according to the Table 1 . Positive rates of TTV, TTV1, TTV2, and co-infection of TTV1 and TTV2 in farm A were higher than in farm B (Figure 3).
Analysis of the obtained sequences from the seven breeds of pig revealed a lower genetic diversity within genogroup variant, but a high genetic diversity between genogroups. The pair wise comparison of nucleotide sequences within a genogroup showed high percentage of homology (90.9\%-99.2\% among TTV1, 86.4\%-100\% among TTV2) (Table 3 and Table 4). The percentage of sequence identity among different variants was not obviously associated with swine breeds. Diversity between genogroup 1 and 2 sequences was high, showing overall sequences identities of only $42-56 \%$. Comparison of TTV sequences from the breeds of swine with

Table 2 Prevalence of TTV genogroups in different sexes and breeds of swines

\begin{tabular}{|c|c|c|c|c|c|c|c|c|c|}
\hline \multirow[t]{3}{*}{ gender } & \multirow[t]{3}{*}{ Breed } & \multicolumn{8}{|c|}{ Prevalence of swine TTV genogroup } \\
\hline & & \multicolumn{2}{|c|}{ TTV1 or TTV2 } & \multicolumn{2}{|c|}{ TTV1 } & \multicolumn{2}{|c|}{ TTV2 } & \multicolumn{2}{|c|}{ TTV1 and TTV2 } \\
\hline & & Positive & Prevalence & Positive & Prevalence & Positive & Prevalence & Positive & Prevalence \\
\hline \multirow[t]{7}{*}{ Male } & Rangchang pig $(n=20)$ & 19 & $95.0 \%$ & 18 & $90.0 \%$ & 9 & $45.0 \%$ & 8 & $40.0 \%$ \\
\hline & Chenghua pig $(n=11)$ & 11 & $100.0 \%$ & 9 & $81.8 \%$ & 8 & $72.7 \%$ & 7 & $63.6 \%$ \\
\hline & Zibet pig $(n=6)$ & 6 & $100.0 \%$ & 6 & $100.0 \%$ & 6 & $100.0 \%$ & 6 & $100.0 \%$ \\
\hline & Wild boar $(n=8)$ & 7 & $87.5 \%$ & 6 & $75.0 \%$ & 5 & $62.5 \%$ & 4 & $50.0 \%$ \\
\hline & Duroc pig $(n=18)$ & 18 & $100.0 \%$ & 15 & $83.3 \%$ & 18 & $100.0 \%$ & 15 & $83.3 \%$ \\
\hline & Landrace pig $(n=13)$ & 12 & $92.3 \%$ & 12 & $92.3 \%$ & 11 & $84.6 \%$ & 11 & $84.6 \%$ \\
\hline & Yorkshire pig $(n=5)$ & 5 & $100.0 \%$ & 3 & $60.0 \%$ & 5 & $100.0 \%$ & 3 & $60.0 \%$ \\
\hline \multirow[t]{7}{*}{ Female } & Rangchang pig $(n=60)$ & 57 & $95.0 \%$ & 37 & $61.7 \%$ & 47 & $95.0 \%$ & 27 & $45.0 \%$ \\
\hline & Chenghua pig $(n=14)$ & 12 & $85.7 \%$ & 11 & $78.6 \%$ & 11 & $78.6 \%$ & 10 & $71.4 \%$ \\
\hline & Zibet $\operatorname{pigB}(n=4)$ & 4 & $100.0 \%$ & 3 & $75.0 \%$ & 4 & $100.0 \%$ & 3 & $75.0 \%$ \\
\hline & Wild boarC $(n=12)$ & 12 & $100.0 \%$ & 9 & $75.0 \%$ & 11 & $91.7 \%$ & 8 & $66.7 \%$ \\
\hline & Duroc pig $(n=14)$ & 14 & $100.0 \%$ & 14 & $100.0 \%$ & 14 & $100.0 \%$ & 14 & $100.0 \%$ \\
\hline & Landrace pig $(\mathrm{n}=12)$ & 12 & $100.0 \%$ & 9 & $70.2 \%$ & 12 & $100.0 \%$ & 9 & $70.2 \%$ \\
\hline & Yorkshire pig $(n=11)$ & 11 & $100.0 \%$ & 10 & $90.9 \%$ & 11 & $100.0 \%$ & 10 & $90.9 \%$ \\
\hline
\end{tabular}

Number of analyzed serum samples from different breeds and genders in different sources ( $\mathrm{n}$ ), total amount of positive animals (Positive) and prevalence of in percentage (Prevalence). 


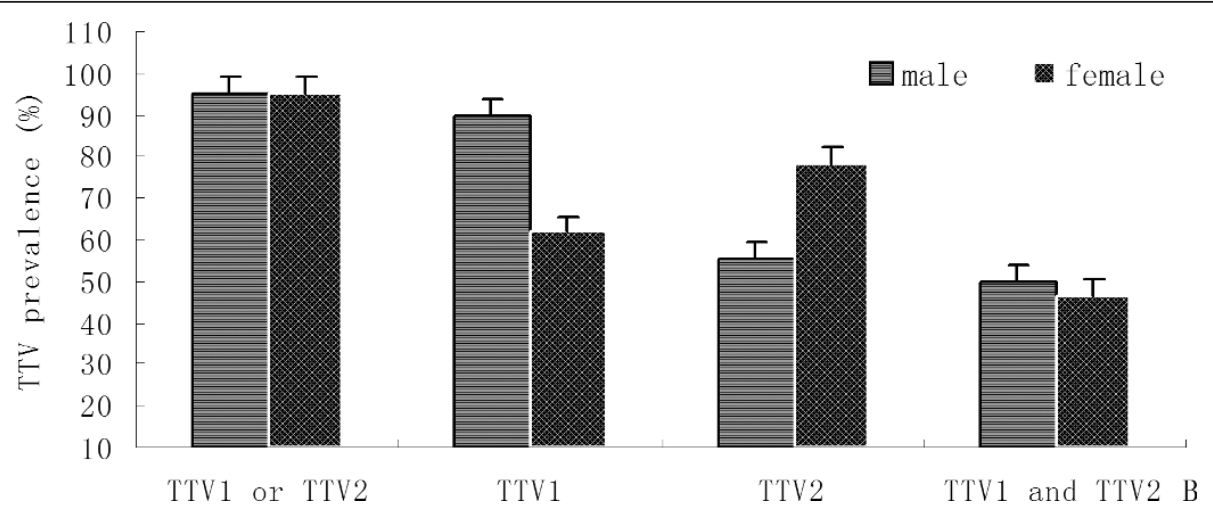

Figure 2 Mean prevalence of TTV genogroup 1 or TTV genogroup 2, TTV genogroup 1, TTV genogroup 2, and co-infection of both TTV geongroups in Rongchang swines from different sexes.

that of Genbank reported revealed high identities on average, over $91 \%$ and $94 \%$ for TTV1 and TTV2, respectively. Genetic distances were similar to the percentage identity value between the seven swine breeds.

\section{Discussion}

The presence of TTV is increasingly reported around the world, particularly in human and swine $[12,27]$. The present study represented the first description of TTV genogroups infection in different breeds of pig populations by serum samples detected using the nested PCR methods in China. Results indicated a high prevalence of TTV genogroup 1 (77.9\%) and 2 (82.2\%) in the seven breeds of pigs, similar to that of other regions swines [12]. No significant differences of TTV prevalence were observed in different breeds. However, Zhu et al [28] reported that the prevalence of TTV1 and TTV2 were at $8.57 \%$ and $6.03 \%$, respectively, no pigs were found to be infected with both TTV1 and TTV2 in chinese swine herds by stools analysis. Moreover, in many countries TTV genogroup 2 has higher prevalence than genogroup 1[16], while in this study all infection rates of both TTV genogroups were very high, and no significant difference was observed between the TTV1 and TTV2. Thus, it may be inferred that, besides swine breeds, TTV prevalence could be caused by surroundings, conditions of farms, and variation of the "virues".

To date, two species-specific TTV genogroups, TTV1 and TTV2, has been described in swine [18]. The extent of nucleotide sequence variation between both TTV genogroups depended greatly on the region of the viral genome analysed $[12,20]$. In this study, the sequencing results showed that TTV nucleotide similarity in different porcine breeds were $92 \%$ to $96 \%$ and $91 \%$ to $100 \%$ comparing with porcine TTV sequences obtained in the Genbank for TTV genogroup 1 and 2, respectively. Therefore, in the seven swine breeds, it is not found new TTV genogroups or clusters.

Interestingly, many studies reported that TTV genogroup 2 prevalence was very high in female swines $[4,12,20,23]$. In this study, the result was not only further confirmed, but also we found high prevalence of

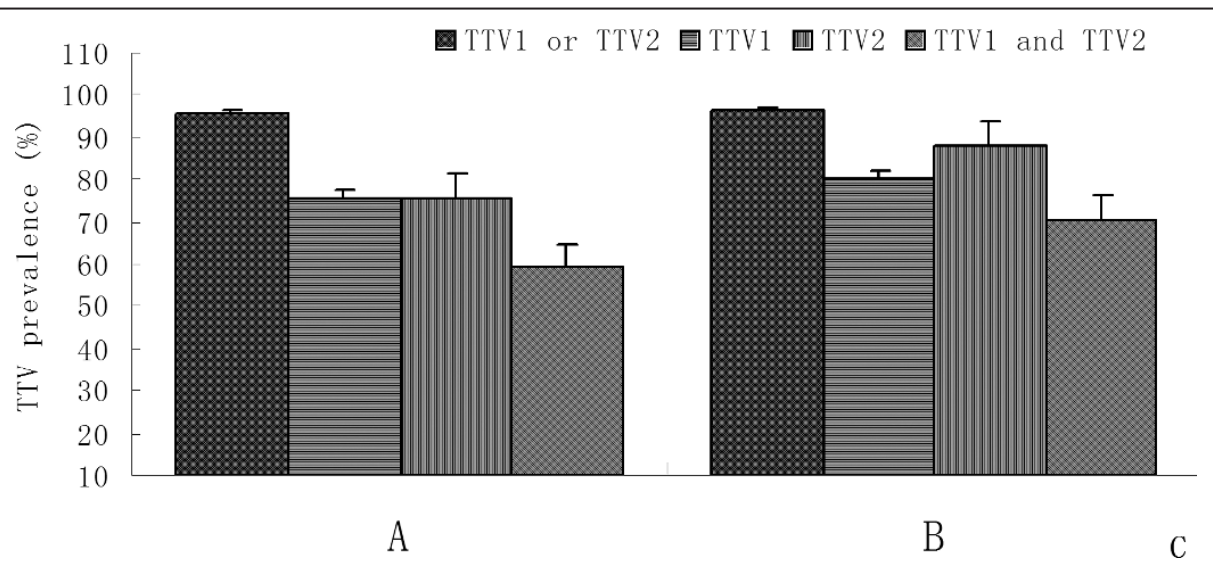

Figure 3 Mean prevalence of TTV genogroup 1 or TTV genogroup 2, TTV genogroup 1, TTV genogroup 2, and co-infection of both TTV geongroups in the seven swine breeds from different farms. 
Table 3 Homoloy analysis of TTV1 UTR sequence

\begin{tabular}{lccccccc}
\hline list & Zibet pig & Chenghua pig & Duroc & Landrace & Large Yorkshire & Rongchang pig & Wild boar \\
\hline Zibet pig & 100 & 95.1 & 97.0 & 93.5 & 95.8 & 92.4 & 92.8 \\
Chenghua pig & 95.1 & 100 & 93.5 & 93.2 & 92.8 & 92.0 & 92.4 \\
Duroc & 97.0 & 93.5 & 100 & 92.0 & 94.3 & 91.3 & 91.3 \\
Landrace & 93.5 & 93.2 & 92.0 & 100 & 92.8 & 91.6 & 99.2 \\
Large Yorkshire & 95.8 & 92.8 & 94.3 & 92.8 & 100 & 95.8 & 92.0 \\
Rongchang pig & 92.4 & 92.0 & 91.3 & 91.6 & 95.8 & 100 & 90.9 \\
Wild boar & 92.8 & 92.4 & 91.3 & 99.2 & 92.0 & 90.9 & 100 \\
\hline
\end{tabular}

both TTV genogroups existed in male swines. In both sexes, co-infections of both TTV genogroups were very higher in the other breeds except Rongchang pig. But one study found that co-infection of both TTV genogroups was not observed in swine stools detected using regular PCR methods [28]. By analyzing the phenomena, it might be caused by the factors, such as different detected samples and methods, physiological functions and micro-ecological conditions of the swine breeds. Some studies has reported that changes of gut microbiome may be associated with bowel diseases or obesity [29].

In humans, TTV has been detected in faeces, saliva, semen, sera, umbilical cord blood and aborted, and slaughterhouse collected foetuses, suggesting both horizontal and vertical transmission as routes of viral dissemination [17,20,30-32]. Also, swine TTV has been found in sera, plasma, faeces and veterinary vaccines, and the results indicated faecal-oral transmission and injection of vaccines as the most significant ways of transmission [33,34]. Recent studies reported that TTV was also distributed in swine tissues included brain, lung, mediastinal and mesenteric lymph nodes, heart, liver, spleen, kidney and bone marrow in different ages [35]. In this study, prevalence of TTV genogroups detected was higher in serum samples of the adults than in the young swines, indicating that vertical transmission by blood contributed to the spread of virus. This result further confirmed the fact that swine TTV can be transmitted vertically through sow-to-piglet [31].

According to the different farms, TTV prevalences of seven swine breeds were also analyzed. In the farm A and $\mathrm{B}$, no significant differences were observed in all serum samples detected. However, if swine feeding and living conditons would effect on TTV prevalence, the same swine breed, Rongchang pig, which lived in the two independent farms, was detected. The results showed that the conditions were not influence on TTV prevalence in Rongchang pig. This indicated that difference of TTV infection was caused by swine breed. Furthermore, sequence analysis indicated that homology of TTV was very high (over 91\%) in the seven swine breeds. Therefore, the theory of horizontal or vertical transmission of TTV was further supported by evidences obtained in the study.

\section{Conclusion}

The results of the present study showed that TTV prevalence were ubiquitous distribution in different swine breeds, and the breeds were one of these factor caused TTV prevalence difference. While many studies found that PMWS and PRRSV infections in swine populations were associated with prevalence of TTV genogroup 2 and 1 , respectively $[12,15,36]$. Therefore, further studies on the detailed pathogenicity, prevention, treatment and diagnosis of TTV in pig populations, including the relationship of the virus with PMWS, PRRS, and other swine diseases, are needed.

\section{Materials and methods}

Serum samples were collected between April and December in 2009 at two independent farms, which are about $300 \mathrm{~km}$ apart and are carried out the nearly same management models and feeding program, and

Table 4 Homology Analysis of TTV2 UTR sequence

\begin{tabular}{|c|c|c|c|c|c|c|c|}
\hline list & Zibet pig & Chenghua pig & Duroc & Landrace & Large Yorkshire & Rongchang pig & Wild boar \\
\hline Zibet pig & 100 & 87.4 & 88.3 & 86.4 & 88.3 & 88.3 & 89.3 \\
\hline Chenghua pig & 87.4 & 100 & 96.3 & 93.0 & 97.6 & 96.3 & 94.1 \\
\hline Duroc & 88.3 & 96.3 & 100 & 91.6 & 98.1 & 100 & 92.6 \\
\hline Landrace & 86.4 & 93.0 & 91.6 & 100 & 91.2 & 91.6 & 92.6 \\
\hline Large Yorkshire & 88.3 & 97.6 & 98.1 & 91.2 & 100 & 95.8 & 94.1 \\
\hline Rongchang pig & 88.3 & 96.3 & 100 & 91.6 & 95.8 & 100 & 92.6 \\
\hline Wild boar & 89.3 & 94.1 & 92.6 & 92.6 & 94.1 & 92.6 & 100 \\
\hline
\end{tabular}


artificially insemination were taken in swine production system (table 1). A total of 208 serum samples of seven breeds of swine (Rongchang pig, Zibet pig, Chenghua pig, and wild boar; Duroc, Landrace, and Large Yorkshire), which were randomly collected from age groups (post-weaning piglets [1-2 month of age], $\mathrm{n}=105$; subadult pigs [3-6 months of age], $\mathrm{n}=59$; and adults [over 12 months of age], $\mathrm{n}=44$ ), and gender (female, $\mathrm{n}=$ 127; male, $\mathrm{n}=81$ ), were detected to obtain an overview of the presence of TTV using UTR nested PCR methods. About 10 to 42 serum samples were collected per studied breed. All of the animal experiments in the study were healthy and were carried out in accordance with the guidelines of Sichuan Province on the Review of Welfare and Ethics of Laboratory Animals, and under the protocol (SCU-AM-2010-01221) approved by the Animal Ethics Committee of Sichuan University.

Blood samples were centrifuged at $1500 \times \mathrm{g}$ for 10 min at $4^{\circ} \mathrm{C}$, and obtained sera were stored at $-80^{\circ} \mathrm{C}$ prior to usage. Viral DNA was extracted from $200 \mu \mathrm{l}$ of the serum samples using the QIAamp DNA Blood Mini Kit (Qiagen, China). The entire extraction process were performed according to the manufacturer's instructions and the DNA was eluted in $50 \mu \mathrm{L}$ elution buffer. Presence of TTV genogroup 1 or TTV genogroup 2 in serum samples was determined using previously described nested PCR methods [19], the reaction and amplification conditions were slightly modified from previously described systems. For TTV genogroup 1, first round $25 \mu \mathrm{L}$ PCR reactions contained $5 \mu \mathrm{L}$ of serum DNA, 20 pmol primer forward-1 (5'-CGG GTTCAGGAGGCTCAAT-3') and reverse-1 (5'-GCCATTCGGAACTGCACTTAC T3'), $2.5 \mathrm{mM}$ dNTP, $2 \mathrm{mM} \mathrm{MgCl}$ and $0.5 \mathrm{U}$ Taq DNA polymerase (Promega, USA). The amplification was initiated by heating for $5 \mathrm{~min}$ at $94^{\circ} \mathrm{C}$, followed by 35 cycles of $30 \mathrm{~s}$ at $94^{\circ} \mathrm{C}, 30 \mathrm{~s}$ at $54^{\circ} \mathrm{C}, 40 \mathrm{~s}$ at $72^{\circ} \mathrm{C}$ and a final extension for $5 \mathrm{~min}$ at $72^{\circ} \mathrm{C}$. Then, $5 \mu \mathrm{L}$ of the serum amplification product was used as the template for nested PCR using primers pair forward nested-1(5'CTCGCTTCGCTCGCACCAC-3') and reverse nested- 1 (5'-CAGTTTACTGGGA ACGCCCTAATTCT-3') 20 pmol each primer, $2.5 \mathrm{mM}$ dNTP, $2 \mathrm{mM} \mathrm{MgCl}$ and $0.75 \mathrm{U}$ Taq DNA polymerase initiated for $5 \mathrm{~min}$ at $94^{\circ}$ $\mathrm{C}$, followed by 35 cycles of $25 \mathrm{~s}$ at $94^{\circ} \mathrm{C}, 25 \mathrm{~s}$ at $56^{\circ} \mathrm{C}$, $30 \mathrm{~s}$ at $72^{\circ} \mathrm{C}$ and a final extension for $5 \mathrm{~min}$ at $72^{\circ} \mathrm{C}$. For TTV genogroup 2, the amplification step was carried out as described above using primers pairs forward-2 (5'-AGTTACACATAACCACCAAACC-3') and reverse2(5'-ATTACCGCCTGCCCGATAGG C-3') for the first round and forward nested-2 (5'-CCAAACCACAGGAAACTGTGC-3') and reverse nested-2(5'CTTGACTCCGCTCTCAGGAG-3') for the nested PCR. The first round amplification was initiated by heating for $5 \mathrm{~min}$ at $94^{\circ} \mathrm{C}$, followed by 35 cycles of $25 \mathrm{~s}$ at $94^{\circ} \mathrm{C}$,
$25 \mathrm{~s}$ at $52^{\circ} \mathrm{C}, 30 \mathrm{~s}$ at $72^{\circ} \mathrm{C}$ and a final extension for 5 min at $72^{\circ} \mathrm{C}$. The nested PCR amplification was performed as above except the annealing temperature was changed to $55^{\circ} \mathrm{C}$. The second round amplification products of TTV genogroup 1 and TTV genogroup 2 were analyzed using electrophoresis on a $2 \%(\mathrm{w} / \mathrm{v})$ agarose gel and were visualized with Sybrsafe (Invitrogen, Canada).

A total of 14 nested PCR positive amplicons (one TTV1 and one TTV2 were chosen per breed) were randomly selected and sequenced to validate the nested PCR amplification results and to analyze the similarities among TTV genogroups of different breeds. The 14 products amplified were excised from $1 \%$ agarose gel and purified using the QIAquick PCR Purification Kit (Qiagen) according to the manufacturer's instructions. Sequencing reaction were done using Big Dye Terminator v3.1 cycle sequencing kit (Biosystem) and ran with ABI Prism 3100 sequence analyzer (Perkin-Elmer). Nucleotide sequences were edited using VectorNTI and aligned with partial loaded sequence of the swine TTV UTR in Genbank nucleotide database using the WU_BLAST 2.0 programs.

Statistical analysis were carried out for detected amounts of TTV infection in seven breeds of pig among the different breeds, farms, age groups, and genders using SPSS software. Level of statistical significance was fixed at a $P$ value $<0.05$.

\section{Abbreviations}

TTV: Torque teno virus; TTV1: Torque teno virus group 1; TTV2: Torque teno virus group 2; ssDNA: single-stranded, and negative sense DNA; nested PCR: nested polymerase chain reaction; PCV2: porcine circovirus type 2; PMWS: postweaning multisystemic wasting syndrome; PRRS: porcine reproductive and respiratory syndrome; TTSuV: Torque teno sus viruses; ORF: open reading frames; UTR: untranslated region.

\section{Acknowledgements}

This work was funded by Chinese Ministry of Scinence and Technology (project number:2007BAD51B05). Authors are thankful to Professor Hongning Wang for giving such valuable advice.

\section{Authors' contributions}

ZW carried out the design of the study, most of the experiments and wrote the manuscript. HW participated in revising the manuscript and the experimental design. $X Y, Z G$, and $Y Z$ participated in acquisition, analysis and interpretation of data. All authors read and approved the final manuscript.

\section{Competing interests}

The authors declare that they have no competing interests.

Received: 29 August 2011 Accepted: 3 November 2011 Published: 3 November 2011

\section{References}

1. Nishizawa T, Okamoto H, Konishi K, Yoshizawa H, Miyakawa Y, Mayumi M: A novel DNA virus (TTV) associated with elevated transaminase levels in posttransfusion hepatitis of unknown etiology. Biochem Biophys Res Commun 1997, 241:92-97.

2. Biagini P: Classification of TTV and related virus (anelloviruses). Curr Top Microbiol Immunol 2009, 331:21-23. 
3. Okamoto H, Takahashi M, Nishizawa T, Tawara A, Fukai K, Muramatsu U, Naito Y, Yoshikawa A: Genomic characterization of TT viruses (TTVs) in pigs, cats and dogs and their relatedness with species-specific TTVs in primates and tupaias. J Gen Virol 2002, 83:1291-1297.

4. Gallei A, Pesch S, Esking WS, Keller C, Ohlinger VF: Porcine Torque teno virus: determination of viral genomic loads by genogroup-specific multiplex rt-PCR, detection of frequent multiple infections with genogroups 1 or 2 , and establishment of viral full-length sequences. Vet Microbiol 2010, 143:202-212.

5. Krakowka S, Ellis J: Evaluation of the effects of porcine genogroup 1 torque teno virus in gnotobiotic swine. Am J Vet Res 2008, 69:1623-1629.

6. Biagini P, Charrel RN, de Micco P, de Lamballerie X: Association of $T T$ virus primary infection with rhinitis in a newborn. Clin Infect Dis 2003, 36:128-129.

7. Gergely P Jr, Blazsek A, Danko K, Ponyi A, Poor G: Detection of TT virus in patients with idiopathic inflammatory myopathies. Ann NY Acad Sci 2005, 1050:304-313.

8. Kasirga E, Sanlidag T, Akcali S, Keskin S, Aktas E, Karakoc Z, Helvaci M, Sozen G, Kuzu M: Clinical significance of $\Pi$ virus infection in children with chronic hepatitis B. Pediatr Int 2005, 47:300-304.

9. Pifferi M, Maggi $F$, Andreoli E, Lanini L, Marco ED, Fornai C, Vatteroni ML, Pistello M, Ragazzo V, Macchia P, Boner A, Bendinelli M: Associations between nasal torquetenovirus load and spirometric indices in children with asthma. J Infect Dis 2005, 192:1141-1148.

10. Tomasiewicz K, Modrzewska R, Lyczak A, Krawczuk G: TT virus infection and pancreatic cancer: relationship or accidental coexistence. World J Gastroenterol 2005, 11:2847-2849.

11. Ellis J, Allan G, Krakowka S: Effect of coinfection with genogroup1 porcine torque teno virus on porcine circovirus 2-associated postweaning multisystemic wasting syndrome in gnotobiotic swine. Am J Vet Res 2008, 69:1608-1614.

12. Kekarainen $T$, Sibila M, Segales J: Prevalence of swine Torque teno virus in post-weaning multisystemic wasting syndrome (PMWS)-affected and non-PMWS-affected pigs in Spain. J Gen Virol 2006, 87:833-837.

13. Krakowka S, Hartunian C, Hamberg A, Shoup D, Rings M, Zhang Y, Allan G, Ellis J: Evaluation of induction of porcine dermatitis and nephropathy syndrome in gnotobiotic pigs with negative results for porcine circovirus type 2. Am J Vet Res 2008, 69:1615-1622.

14. Savic B, Milicevic V, Kureljusic B, Ivetic V, Pavlovic I: Detection rates of the swine torque teno viruses (TTVs), porcine circovirus type 2 (PCV2) and hepatitis $\mathrm{E}$ virus (HEV) in the livers of pigs with hepatitis. Vet Res Commun 2010, 34:641-648.

15. Taira O, Ogawa H, Nagao A, Tuchiya K, Nunoya T, Ueda S: Prevalence of swine Torque teno virus genogroups 1 and 2 in Japanese swine with suspected post-weaning multisystemic wasting syndrome and porcine respiratory disease complex. Vet Microbiol 2009, 139:347-350.

16. Kekarainen $\mathrm{T}$, Segalés J: Torque teno virus infection in the pig and its potential role as a model of human infection. Vet J 2009, 180:163-168.

17. Okamoto H: TT viruses in animals. Curr Top Microbiol Immunol 2009, 331:35-52.

18. Niel C, Diniz-Mendes L, Devalle S: Rolling-circle amplification of Torque teno virus (TTV) complete genomes from human and swine sera and identification of a novel swine TTV genogroup. J Gen Virol 2005, 86:1343-1347.

19. Segalés J, Martínez-Guinó L, Cortey M, Navarro N, Huerta E, Sibila M, Pujols J, Kekarainen T: Restrospecctive study on swine Torque teno virus genogroups 1 and 2 infection from 1985 to 2005 in Spain. Vet Microbiol 2009, 134:199-207.

20. Bigarre L, Beven V, de Boisseson C, Grasland B, Rose N, Biagini P, Jestin A: Pig anelloviruses are highly prevalent in swine herds in France. $J$ Gen Virol 2005, 86:631-635.

21. Liu X, Gu W, Guo X, Ge X, Chen Y, Yang H: Prevalence of torque teno virus infection in pig herds in China. Vet Rec 2011, 168:410.

22. Martelli F, Caprioli A, Di Bartolo I, Cibin V, Pezzotti G, Ruggeri FM, Ostanello F: Detection of Swine torque teno virus in italian pig herds. J Vet Med B Infect Dis Vet Public Health 2006, 53:234-238.

23. McKeown NE, Fenaux M, Halbur PG, Meng XJ: Molecular characterization of porcine $\Pi$ virus, an orphan virus, in pigs from six different countries. Vet Microbiol 2004, 104:113-117.
24. Martínez L, Kekarainen T, Sibila M, Ruiz-Fons F, Vidal D, Gortazar C, Segalés J: Torque teno virus (TTV) is highly prevalent in the European wild boar (Sus scrofa). Vet Microbiol 2006, 118:223-229.

25. Ng TFF, Suedmeyer WK, Wheeler E, Gulland F, Breitbart M: Novel anellovirus discovered from a mortality event of captive California sea lions. J Gen Virol 2009, 90:1256-1261.

26. Huang YW, Ni YY, Dryman BA, Meng XJ: Multiple infection of porcine Torque teno virus in a single pig and characterization of the full-length genomic sequences of four U.S. prototype PTTV strains: implication for genotyping of PTTV. Virology 2010, 396:289-297.

27. Hino S, Miyata H: Torque teno virus (TTV): current status. Rev Med Virol 2007, 17:45-57.

28. Zhu CX, Cui L, Shan TL, Luo XN, Liu ZJ: Porcine torque teno virus infections in China. J Clin Virol 2010, 48:296-298.

29. Ley RE, Turnbaugh PJ, Klein S, Gordon Jl: Microbial ecology: human gut microbes associated with obesity. Nature 2006, 444:1022-1023.

30. Komatsu H, Inui A, Sogo T, Kuroda K, Tanaka T, Fujisawa T: TTV infection in children born to mothers infected with TTV but not with HBV, HCV, or HIV. J Med Virol 2004, 74:499-506.

31. Martínez-Guinó L, Sibila M, Kekarainen T, Martín-Valls G, Segalés J: Evidence of Torque teno virus (TTV) vertical transmission in swine. Theriogenolgy 2009, 71:1390-1395.

32. Matsubara H, Michitaka K, Horiike N, Kihana T, Yano M, Mori T, Onji M: Existence of $\Pi$ virus DNA and TT-like mini virus DNA ininfant cord blood: mother-to-neonatal transmission. Hepatol Res 2001, 21:280-287.

33. Brassard J, Gagne MJ, Lamoureux L, Inglis GD, Leblanc D, Houde A: Molecular detection of bovine and porcine Torque teno virus in plasma and faeces. Vet Microbiol 2008, 126:271-276.

34. Kulcsar G, Farsang A, Soos T: Testing for viral contaminants of veterinary vaccines in Hungary. Biologicals 2010, 38:346-349.

35. Aramouni M, Segalés J, Cortey $M$, Kekarainen T: Age-related tissue distribution of swine Torque teno sus virus 1 and 2. Vet Microbiol 2010, 146:350-353

36. Segalés J, Allan GM, Domingo M: Porcine circovirus diseases. Anim Health Res Rev 2005, 6:119-142.

doi:10.1186/1743-422X-8-503

Cite this article as: Wu et al:: Molecular detection of Torque teno virus in different breeds of swine. Virology Journal 2011 8:503.

\section{Submit your next manuscript to BioMed Central and take full advantage of:}

- Convenient online submission

- Thorough peer review

- No space constraints or color figure charges

- Immediate publication on acceptance

- Inclusion in PubMed, CAS, Scopus and Google Scholar

- Research which is freely available for redistribution

Submit your manuscript at www.biomedcentral.com/submit
C Biomed Central 